\title{
NONLINEAR CONTROL FOR A DIESEL ENGINE: A CLF-BASED APPROACH
}

\author{
Olena KUZMYCH*, Abdel AitouCHE**, Ahmed El HAJJAJI* , Jerome BosChE* \\ * MIS Laboratory \\ University of Picardie Jules Verne, 33 rue Saint Leu, 80039 Amiens Cedex 1, France \\ e-mail: kuzmych79@gmail.com, \{ahmed.hajjaji,jerome.bosche\}@u-picardie.fr \\ ${ }^{* *}$ LAGIS CNRS 8219 \\ Graduate School of Engineering, 13 rue de Toul, 59000 Lille, France \\ e-mail:abdel.aitouche@hei.fr
}

\begin{abstract}
In this paper, we propose a control Lyapunov function based on a nonlinear controller for a turbocharged diesel engine. A model-based approach is used which predicts the experimentally observed engine performance for a biodiesel. The basic idea is to develop an inverse optimal control and to employ a Lyapunov function in order to achieve good performances. The obtained controller gain guarantees the global convergence of the system and regulates the flows for the variable geometry turbocharger as well as exhaust gas recirculation systems in order to minimize the $N O_{x}$ emission and the smoke of a biodiesel engine. Simulation of the control performances based on professional software and experimental results show the effectiveness of this approach.
\end{abstract}

Keywords: turbocharged diesel engine, control Lyapunov function, nonlinear control design, stability analysis, diesel virtual test bench.

\section{Introduction}

Ecological and economical environmental requirements have increased over the last years. Therefore, engines with low fuel consumption and toxic exhaust emissions are required. Thus, very important problems are identification and fault diagnosis of an automotive diesel engine (Simani, 2013; Boulkroune et al., 2013) and optimal control strategies. Therefore, advances in model based control theory are the key demands on modern technologies (cf. Wahlstrom and Eriksson, 2011a; Tomera, 2010; Cook et al., 2006; Delaleau et al., 2001). Known control strategies are presented also by Yarza et al. (2013) as well as Witkowska and Śmierzchalski (2012).

To fulfill the requirements, technologies like exhaust gas recirculation (EGR) and variable geometry turbine (VGT) have been introduced. The basic performance requirements for automotive engines such as transient response, fuel economy, and emissions are often contradictory and require judicious tradeoffs at every stage of the design process. This tradeoff can be avoided by employing and manipulating EGR and VGT actuators in order to achieve the control objective, which is to supply an amount of air and a fraction of appropriate
EGR for given operating conditions. The emissions can be reduced by increasing the intake manifold EGR-fraction, and the smoke can be reduced by increasing the air/fuel ratio (Kao and Moskwa, 1995). These are main reasons why diesel engines are solutions for technical applications due to their low fuel consumption and durability. Much of the energy demand is from the transportation sector, which is predominantly accommodated with petroleum-based fuels. At the same time, biodiesel is an attractive alternative to diesel, produced from vegetable oils or animal fats. These alternative fuels are gaining importance as a means of reducing petroleum dependence and green house gas emissions. Biodiesel is an attractive renewable fuel, but it typically results in increased emissions of nitrogen oxides $N O_{x}$ relative to diesel (Adi et al., 2009).

Designing coordinated control is a difficult problem because the presence of both the VGT and EGR in the intake airflow path introduces varying degrees of complexities. Various approaches to control of EGR and the VGT for emission reduction have been published. Cook et al. (2006) and Jankovic et al. (2000) present a good overview of various control aspects of diesel engines with EGR and the VGT, and give a comparison 
of some control approaches with different selections of performances.

A well-known approach has been presented by Takagi and Sugeno (1985) as well as Tanaka and Wang (2001) for fuzzy identification of nonlinear control systems using a linear matrix inequality approach that is very useful for nonlinear control problems. For example, in the paper of Djemili et al. (2012) the control strategy of a diesel engine air path described by a Takagi-Sugeno (TS) model is presented. In this approach a mean value model of a diesel engine can be transformed into a TS model, and the gains of the adaptive observer and the feedback controller are obtained by solving linear matrix inequalities derived from Lyapunov theory.

Similar work has been done by Abidi et al. (2013) in order to design fuzzy robust tracking control with pole placement for a diesel engine. Zemouche et al. (2004) presented another interesting approach to nonlinear system interpretation based on the differential mean value theorem in order to design an observer for nonlinear systems. It was applied for a diesel engine model by Kuzmych et al. (2012). Gain scheduling control for a diesel engine model is used very often (see, e.g., Wahlstrom et al., 2005; Lansky, 2008).

In this paper, we develop a nonlinear control design based on the control Lyapunov function (CLF) which was proposed by Jankovic et al. (1998) and extended with an integral action by Wahlstrom and Eriksson (2011b). The proposed approach will extend from a trivial quadratic Lyapunov function case considered in various LPV approaches to a more general Lyapunov function with an additional degree of freedom. Compared with quadratic Lyapunov functions, this generalized Lyapunov function will help to construct the resulting nonlinear control law so that the design objective is optimized with respect to a given cost functional for good performance.

Our paper extends the work of Jankovic et al. (1998), since we develop a nonlinear controller for the diesel engine. We briefly review the control design presented in this work and by Sepulchre et al. (1997), analyze the stability of this structure, and compare the results of Jankovic et al. (1998) with our more general control Lyapunov function, which leads to improved performance control. This nonlinear control approach yields a fast increase in the air intake, and slow degradation in performances.

The design steps include construction of a Lyapunov function, inverse optimal control, and a nonlinear input transformation (Utkin, 1992). The CLF is constructed as a Lyapunov function for the closed-loop system with a feedback linearizing controller. The controller is then derived from the Lyapunov function for the desired mass flow rate of EGR and the desired turbine mass flow rate. For this approach, it is necessary to invert the flow model to obtain the EGR valve position and the VGT vane position which represent the control inputs to the model reported by Stefanopoulou et al. (2000) and Upadhyay et al. (2002).

The design objectives are to regulate the air-fuel ratio and the EGR fraction to their respective setpoints determined by the operating conditions during quasi-steady state operation. The compressor mass flow and the exhaust manifold pressure are chosen as outputs. Therefore, the setpoints for the air/fuel ratio and the EGR fraction can be transformed to setpoints for the compressor mass flow and the exhaust manifold pressure. The proposed controller is tested at the operating points using the look-up table obtained from test experiments of biodiesel engine performance and in the virtual testbed simulator AMESim. The real static maps are based on a trade-off between fuel economy and minimal $N O_{x}$ and smoke generation. We discuss the advantages of the nonlinear CLF-based controller in order to evaluate the experimental benefits in the testbed.

This paper is organized as follows. In Section 2 the turbocharged diesel engine testbed Caterpillar and the virtual testbench AMESim are described, and the dynamic model is introduced in Section 3. After having pointed out the control design problem and the methodology in Section 4, a construction of the control Lyapunov function is presented and a control law is designed in Section 5. This control strategy is successfully evaluated using an advanced diesel engine professional simulator AMESim (LMS) in Section 6, and experimental results in Caterpillar testbed are reported in Section 7. Conclusion and recommendations for future work are presented in the last section.

\section{Turbocharged diesel engine testbed}

2.1. Caterpillar testbed description. Necessary biodiesel experimental tests were conducted on the advanced engine testbed in an automotive laboratory located at the University of Sussex in Brighton. This testbed is built with a Caterpillar 3126b heavy-duty truck engine coupled with a SCHORCH dynamometer controlled by the CP Cadet V12 control and data logging system. The Caterpillar 3126b engine has Caterpillar's hydraulically-actuated electronic unit injector (HEUI) fuel injection system, which can significantly improve combustion efficiency and reduce emission. The employed biodiesel meets the EN14214 specification.

Additionally, a high pressure exhaust gas recirculation system and the Garrett GT3782VA variable geometry turbocharger were installed, which can further improve fuel consumption and reduce emissions like Soot and $N O_{x}$. In order to control the EGR and VGT in real-time, a dSPACE MicroAutoBox 1401/1501 is connected. By receiving relevant signals such as temperature, pressure and flow from the sensors installed 


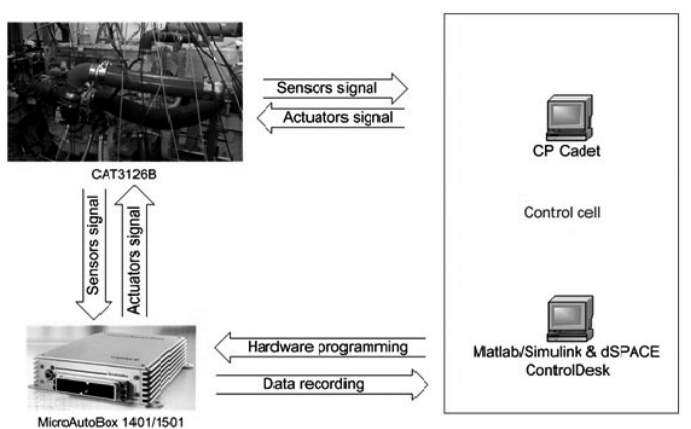

Fig. 1. Block diagram of the CLF-based control law.

around the engine, MicroAutoBox can output control signals to move the EGR and VGT actuators in real-time.

External sensors are used to measure various quantities including temperatures, pressures, torques, air and fuel flows, and exhaust emission. Exhaust emissions sensors are used to measure $\mathrm{CO}_{2}, \mathrm{NO}_{x}$, and PM. These control signals are generated from the control algorithm uploaded into the MicroAutoBox. These sensors and actuators are listed in Tables 1 and 2. The date and the control signal flow are illustrated in Fig. 1. The engine is connected with two control platforms, which are the CP Cadet and the dSPACE control desk. The engine tests are conducted and monitored by the CP Cadet Platform. By uploading the developed VGT and EGR controller to the MicroAutoBox through the Matlab/Simulink platform, the EGR valve and VGT vane positions can be adjusted by the controller output signal from dSPACE ControlDesk in real-time. Testing data can be collected from both platforms and used for data acquisition and analysis. The specifications of the Caterpillar 3126b truck engine are shown in Tables 3-6.

2.2. Virtual test-bench. The operation points for the designed CLF-based and PID control strategy have been simulated on a four-cylinder diesel engine model that was built in LMS AMESim professional software. This is a virtual testbed based on an intuitive graphical interface in which the system is displayed throughout the simulation process. The engine model was developed within the AMESim platform associated with the IFP-Engine library, which is suitable for engine design as well as for strategy validation. A four cylinder turbocharged diesel engine with an EGR loop and a variable nozzle turbine has been simulated. Two heat exchangers are used in this application: one for the EGR path, to cool down the burnt gas (EGR cooler), another one on the intake path to cool down the compressed gas (inter-cooler). The general performance parameters were taken from the static engine
Table 1. Sensors.

\begin{tabular}{|l|}
\hline Inlet temperature sensor \\
\hline Inlet air flow meter \\
\hline Inlet pressure sensor \\
\hline Pre-turbo exhaust pressure sensor \\
\hline Acceleration pedal position sensor \\
\hline Engine speed sensor \\
\hline Inlet manifold oxygen sensor \\
\hline Exhaust manifold oxygen sensor \\
\hline Exhaust opacity sensor (AVL Opacimeter 439) \\
\hline Exhaust emission sensor (Testo 350 Engine test kit) \\
\hline EGR position feedback sensor \\
\hline VGT position feedback sensor \\
\hline
\end{tabular}

Table 2. Actuators.

\begin{tabular}{|l|}
\hline EGR valve drive actuator \\
\hline VGT vanes drive actuator \\
\hline
\end{tabular}

Table 3. Description of the truck engine.

\begin{tabular}{|l|c|}
\hline Model & Caterpillar 3126B \\
\hline Type of engine & In-line, 4-stroke \\
\hline Number of cylinders & 6 \\
\hline Number of inlet valves & 2 \\
\hline Number of exhaust valves & 1 \\
\hline Firing order & $1-5-3-6-2-4$ \\
\hline Type of combustion & Direct injection \\
\hline Maximum torque & $1166 \mathrm{Nm} @ 1440 \mathrm{rpm}$ \\
\hline Maximum power & $224 \mathrm{~kW} @ 2200 \mathrm{rpm}$ \\
\hline Idle speed & $700 \mathrm{rpm}$ \\
\hline Maximum speed & $2640 \mathrm{rpm}$ \\
\hline
\end{tabular}

Table 4. Geometrical characteristics.

\begin{tabular}{|l|c|}
\hline Bore & $110 \mathrm{~mm}$ \\
\hline Stroke & $127 \mathrm{~mm}$ \\
\hline Compression ratio & 16 \\
\hline Total displacement & 7.25 liter \\
\hline Connecting rod length & $199.9 \mathrm{~mm}$ \\
\hline Crank throw radius & $63.5 \mathrm{~mm}$ \\
\hline
\end{tabular}

Table 5. Injection system.

\begin{tabular}{|l|c|}
\hline Type & HEUI \\
\hline Injection pressure & $200-145$ bar \\
\hline Injection orifices No. & 6 \\
\hline Type of combustion & Direct injection \\
\hline
\end{tabular}

Table 6. Geometrical characteristics of manifolds and pipes.

\begin{tabular}{|l|c|}
\hline Intake manifold & $5 \mathrm{~L}$ \\
\hline Exhaust manifold & $0.945 \mathrm{~L}$ \\
\hline
\end{tabular}


Table 7. Nomenclature.

\begin{tabular}{|l|l|}
\hline$\eta_{v o l}$ & Volumetric efficiency \\
\hline$n_{e}$ & Engine speed \\
\hline$n_{c y l}$ & Number of cylinders \\
\hline$V_{d}$ & Volume \\
\hline$R_{a}$ & Gas constant of the air \\
\hline$W_{c}$ & Compressor mass flow \\
\hline$p_{a m b}$ & Ambient pressure \\
\hline$T_{a m p}$ & Ambient temperature \\
\hline$J_{t}$ & Turbocharger moment of inertia \\
\hline$W_{f}$ & Engine fueling rate requested by the driver \\
\hline$\tau$ & Time constant \\
\hline$V_{i m}$ & Intake manifold volume \\
\hline$V_{e m}$ & Exhaust manifold volume \\
\hline$T_{i m}$ & Intake manifold temperature \\
\hline$T_{e m}$ & Exhaust manifold temperature \\
\hline$T_{c}$ & Temperature after the compressor \\
\hline$A_{v g t}$ max & $\begin{array}{l}\text { Maximum area in the turbine that gas flows } \\
\text { through }\end{array}$ \\
\hline$A_{e g r}$ max & Maximum effective area \\
\hline$\gamma_{e}$ & Specific heat capacity ratio of exhaust gas \\
\hline$\gamma_{a}$ & Specific heat capacity ratio for air \\
\hline$R_{e}$ & Exhaust gas constant \\
\hline$c_{p e}$ & $\begin{array}{l}\text { Specific heat capacity at constant pressure for } \\
\text { exhaust gas }\end{array}$ \\
\hline$c_{p a}$ & Specific heat capacity at constant pressure for air \\
\hline$c_{p}$ & Specific heat capacity at constant pressure \\
\hline$c_{v}$ & Specific heat capacity at constant volume \\
\hline$\eta_{t}$ & Turbine isentropic efficiency \\
\hline$\eta_{m}$ & Turbocharger mechanical efficiency \\
\hline$h_{v}$ & Turbocharger efficiency \\
\hline$\eta_{c}$ & Compressor efficiency \\
\hline$p_{i m}$ & Intake manifold pressure \\
\hline$p_{e m}$ & Exhaust manifold pressure \\
\hline & \\
\hline
\end{tabular}

data and the reference values for the operation points were obtained from experiments.

\section{Model description}

In this section, we present a model of a diesel engine equipped with a VGT and an EGR valve. We consider a third order model for the intake flow loop based on the simplifying assumptions that all thermodynamic properties are referenced to air while the intake and exhaust manifold temperature dynamics are insignificant. This approach has been adopted previously by Jankovic et al. (1998). In this paper, we follow Wahlstrom and Eriksson (2011a) to model a cylinder flow and a mass flow through the EGR and VGT systems.

A schematic diagram of a diesel engine is shown in Fig. 2. The turbocharger consists of a variable geometry turbine and a compressor mounted on the same shaft. The turbine takes the energy from the exhaust gas to power the compressor. The mixture of air from the compressor and the exhaust gas coming through the EGR valve is pumped from the intake manifold into the cylinders. The fuel is injected directly into the cylinders and burnt, producing the torque on the crank shaft. The hot exhaust gas is pumped out into the exhaust manifold. A part of the exhaust gas flows from the exhaust manifold through the turbine out of the engine, and the other part is recirculated back into the intake manifold.

3.1. Manifolds. The modeling effort is focused on the gas flows. The intake and the exhaust manifolds are modeled as dynamic systems with two states each, and these are pressures. The standard isothermal model gives

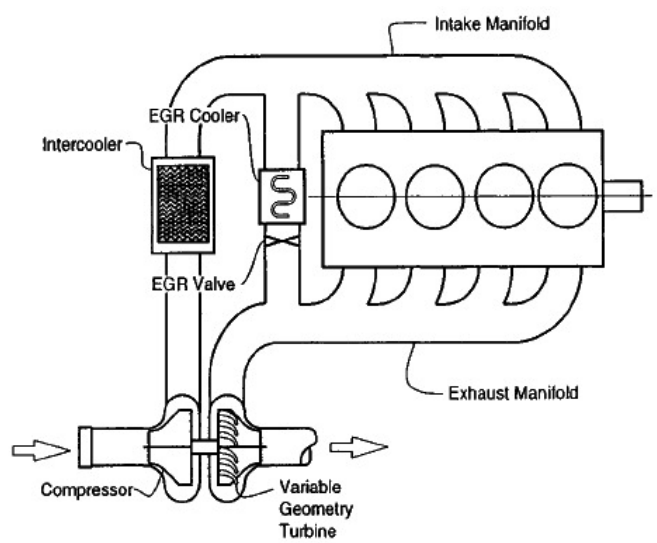

Fig. 2. Turbocharged diesel engine.

the differential equations for the manifold pressures:

$$
\begin{gathered}
\frac{\mathrm{d}}{\mathrm{d} t} p_{i m}=\frac{R_{a} T_{i m}}{V_{i m}}\left(W_{c}+W_{e g r}-W_{e i}\right) \\
\frac{\mathrm{d}}{\mathrm{d} t} p_{e m}=\frac{R_{e} T_{e m}}{V_{e m}}\left(W_{e o}-W_{t}-W_{e g r}\right) .
\end{gathered}
$$

The intake manifold temperature $T_{i m}$ and the exhaust manifold temperature $T_{e m}$ are assumed to be constant.

3.2. Cylinder flow. The total mass flow $W_{e i}$ from the intake manifold into the cylinders is modeled using the volumetric efficiency $\eta_{v o l}$,

$$
W_{e i}=p_{i m} \frac{\eta_{v o l} n_{e} V_{d}}{120 R_{a} T_{i m}}
$$

where $p_{i m}$ and $T_{i m}$ are the pressure and the temperature in the intake manifold, $n_{e}$ is the engine speed and $V_{d}$ is the displaced volume.

Fuel mass flow $W_{f}$ into the cylinders depends on $u_{\delta}$, which gives the injected mass of the fuel,

$$
W_{f}=\frac{10^{-6}}{120} n_{e} n_{c y l} u_{\delta} .
$$


The mass flow $W_{e o}$ out from the cylinders is given by the mass balance as $W_{e o}=W_{f}+W_{e i}$.

3.3. EGR and VGT valves. The mass flow through the EGR valve is modeled by

$$
W_{e g r}=\frac{A_{e g r} \psi_{e g r}}{\sqrt{T_{e m} R_{e}}} p_{e m}
$$

where $\psi_{\text {egr }}$ is modeled as a parabolic function,

$$
\psi_{\text {egr }}=1-\left(\frac{1-\Pi_{\text {egr }}}{1-\Pi_{\text {egropt }}}-1\right)^{2} .
$$

The pressure ratio $\Pi_{e g r}$ is modeled according to

$$
\Pi_{e g r}=\left\{\begin{array}{cl}
\Pi_{\text {egropt }} & \text { if } \quad \frac{p_{i m}}{p_{e m}}<\Pi_{\text {egropt }}, \\
\frac{p_{i m}}{p_{e m}} & \text { if } \Pi_{\text {egropt }} \leq \frac{p_{i m}}{p_{e m}} \leq 1 \\
1 & \text { if } 1<\frac{p_{i m}}{p_{e m}}
\end{array}\right.
$$

The effective area is $A_{\text {egr }}=A_{\text {egr max }} f_{\text {egr }}\left(k_{\text {egr }}\right)$, where $k_{e g r}$ is a position of EGR valve. The compressor mass flow is

$$
W_{c}=\frac{\eta_{c}}{T_{a} c_{p}} \frac{P_{c}}{\left(\frac{p_{i m}}{p_{a}}\right)^{\mu}-1}
$$

the compressor power is

$$
P_{c}=\frac{W_{c} c_{p a} T_{a m b}}{\eta_{c}}\left(\Pi_{c}^{1-\frac{1}{\gamma a}}-1\right),
$$

and the compressor efficiency is

$$
\eta_{c}=\frac{T_{a m b}\left(\Pi_{c}^{1-\frac{1}{\gamma_{a}}}-1\right)}{T_{c}-T_{a m b}} .
$$

The turbine mass flow $W_{t}$ is modeled according to

$$
W_{t}=\frac{A_{v g t \max } f_{\Pi_{t}}\left(\Pi_{t}\right) f_{v g t}\left(k_{v g t}\right) p_{e m}}{\sqrt{T_{e m}} R_{e}},
$$

where $A_{\text {vgtmax }}$ is the maximum area in the turbine that the gas flows through and $k_{v g t}$ is the VGT valve position. This mass flow depends on the VGT actuator signal $k_{v g t}$ and the pressure ratio $\Pi_{t}$ such that $f_{\Pi_{t}}\left(\Pi_{t}\right)=\sqrt{1-\Pi_{t}}$, where $\Pi_{t}=p_{a m b} / p_{\text {em }}$.

3.4. State space model. The model proposed here has three states: the intake manifold pressure $p_{i m}$, the exhaust manifold pressure $p_{e m}$, and the compressor power $P_{c}$, which describe the main dynamics and the most important system properties. The turbocharger dynamic is modeled as a first-order lag power transfer with time constant $\tau$. These states are collected in a state vector $x=\left(p_{i m}, p_{e m}, P_{c}\right)$. Accordingly, our control design model becomes

$$
\begin{aligned}
\dot{p}_{i m} & =k_{1}\left(W_{c}+u_{1}-k_{e} p_{i m}\right), \\
\dot{p}_{e m} & =k_{2}\left(k_{e} p_{i m}-u_{1}-u_{2}+W_{f}\right), \\
\dot{P}_{c} & =\frac{1}{\tau}\left(\eta_{m} P_{t}-P_{c}\right),
\end{aligned}
$$

with nonlinear functions

$$
\begin{aligned}
W_{c} & =\frac{\eta_{c}}{T_{a} c_{p}} \frac{P_{c}}{\left(\frac{p_{i m}}{p_{a}}\right)^{\mu}-1} \\
P_{t} & =\eta_{t} c_{p} T_{e m}\left(1-\left(\frac{p_{a}}{p_{e m}}\right)^{\mu}\right) u_{2},
\end{aligned}
$$

where

$$
k_{1}=\frac{R_{a} T_{i m}}{V_{i m}}, \quad k_{2}=\frac{R_{a} T_{e m}}{V_{e m}}, \quad k_{e}=\frac{\eta_{v} N V_{d}}{R_{a} T_{i m}}
$$

and $\mu=0.28$. Thus, the control goal is to regulate two outputs

$$
y_{1}=W_{c}-W_{c}^{d} \quad y_{2}=W_{e g r}-W_{e g r}^{d}
$$

to zero. We assign $v_{1}=W_{\text {egr }}$ and $v_{2}=W_{t}$, which are the two control inputs, with the assumption that the desired flow values can be assigned by manipulating the EGR and VGT actuators $k_{\text {egr }}$ and $k_{v g t}$. $W_{c}^{d}$ and $W_{e g r}^{d}$ are setpoints of the compressor and the EGR mass flow rates.

In this approach, it is necessary to invert the flow model to obtain the EGR valve position and the VGT vane position commands, which are the control inputs to the model.

\section{Control design}

The design objectives are to regulate the air-fuel ratio and the EGR fraction to their respective setpoints determined from the static engine data,

$$
\begin{gathered}
A F_{r e f}=A F_{r e f}\left(N, W_{f}\right), \\
E G R_{r e f}=E G R_{r e f}\left(N, W_{f}\right) .
\end{gathered}
$$

The generated static maps are based on a trade-off between maximal fuel economy and minimal $N O_{x}$ and smoke generation. Hence, while the setpoint for $A F$ determines the engine response and prevents smoke, the EGR flow fraction seeks to minimize $N O_{x}$ generation in the cylinder. The setpoints of the air-fuel ratio and the EGR fraction can be transformed into the setpoints of the compressor and the EGR mass flow rates $W_{c}^{d}$ and $W_{\text {egr }}^{d}$ using their relationship in steady state, see the work of Jankovic et al. (1998) for details. 
4.1. Control methodology. We choose a feedback control $u(x)$ for the system of the form

$$
\dot{x}=f(x)+g(x) u,
$$

which achieves asymptotic stability.

We follow the methodology given by Jankovic et al. (1998), but instead of a quadratic Lyapunov function we develop a more general Lyapunov function which includes the components of state multiplications, and make this function more "flexible" by providing an additional degree of freedom in order to achieve system stability.

The control Lyapunov function $V(x)$ is a smooth, positive definite function such that

$$
\dot{V}(x)=\frac{\partial V}{\partial x} f(x)+\frac{\partial V}{\partial x} g(x) u<0 .
$$

This condition is equivalent to

$$
L_{g} V(x)=0 \Rightarrow L_{f} V(x)<0 \text {. }
$$

For an appropriately chosen positive scalar domination function $\gamma(\cdot)$, the control low obtained by redesigning

$$
u(x)=-\frac{1}{2} \gamma(V(x))\left(L_{g} V\right)^{T}(x)
$$

is globally stabilized. A sufficient condition for existence of $\gamma$ is that the quadratic part of $V(x)$ be a CLF for the Jacobian linearization of (3).

To apply the domination redesign control law (6), we center the controls for the system (1) $v_{1}$ and $v_{2}$ at their setpoint values and obtain

$$
v_{1}=u_{1}+W_{e g r}^{d}, \quad v_{2}=u_{2}+\left(W_{c}^{d}+W_{f}\right) .
$$

4.2. Feedback transformation and outputs. The first step in our control method is to construct a CLF $V(x)$, which is done by feedback linearization (Jankovic et al., 1998; Isidori, 1989). We employ input-output (IO) linearization to construct a CLF for the diesel engine model. Thus, consider the system (1) with the output vector defined as

$$
\begin{aligned}
& y_{1}=W_{c}-W_{c}^{d}, \\
& y_{2}=W_{e g r}-W_{e g r}^{d} .
\end{aligned}
$$

But before applying the stabilization technique, it is necessary to check the stability of zero dynamics. It was shown by Jankovic et al. (1998) and Upadhyay et al. (2002) that a system has an equilibrium which is unstable. Hence, as stressed above, control design is not meaningful but it is possible to circumvent this problem through output redefinition.
Consider a new set of outputs as defined below, where we replace the output of the EGR flow rate by the exhaust manifold pressure $p_{e m}$,

$$
\bar{y}=\left[\begin{array}{l}
\bar{y}_{1} \\
\bar{y}_{2}
\end{array}\right]=\left[\begin{array}{c}
y_{1} \\
p_{e m}-p_{e m}^{e}
\end{array}\right] .
$$

A change of coordinates consistent with the chosen output gives

$$
\begin{aligned}
\dot{\bar{y}}_{1}= & -a\left(\bar{y}_{1}+W_{c}^{d}-k_{e} p_{i m}\right) \\
& -\frac{1}{\tau}\left(\bar{y}_{1}+W_{c}^{d}\right)-a v_{1}+b v_{2}, \\
\dot{\bar{y}}_{2}= & k_{2}\left(k_{e} p_{i m}+W_{f}\right)-k_{2} v_{1}-k_{2} v_{2}, \\
\dot{p}_{i m}= & k_{1}\left(\bar{y}_{1}+W_{c}^{d}-k_{e} p_{i m}+v_{1}\right),
\end{aligned}
$$

where

$$
\begin{gathered}
a=k_{1} \frac{\mu\left(\frac{p_{i m}}{p_{a}}\right)^{\mu-1}\left(y_{1}+W_{c}^{d}\right)}{\left(\frac{p_{i m}}{p_{a}}\right)^{\mu}-1}, \\
b=\frac{1}{\tau} \eta^{*} \frac{T_{e m}}{T_{a}} \frac{1-\left(\frac{p_{a}}{p_{e m}}\right)^{\mu}}{\left(\frac{p_{i m}}{p_{a}}\right)^{\mu}-1}, \\
\eta^{*}=\eta_{m} \eta_{c} \eta_{t} .
\end{gathered}
$$

To establish the stability of the internal dynamics, we examine the zero dynamics of the system as $\bar{y}=$ $\dot{\bar{y}}=0$ and solve for $v_{1}$ and $v_{2}$. Then after substituting this into $p_{i m}$ dynamics, we obtain stable zero dynamics for the equilibrium $p_{i m}^{e}$. With the zero dynamic stable, the standard stabilization technique for an input-output linearizable system can be applied. The feedback transformation $v=G^{-1}(w-F)$ with the invertible matrix

$$
G=\left(\begin{array}{cc}
-a & b \\
-k_{2} & -k_{2}
\end{array}\right)
$$

yields

$$
\begin{aligned}
& {\left[\begin{array}{l}
v_{1} \\
v_{2}
\end{array}\right]=G^{-1}} \\
& \times\left(\begin{array}{c}
w_{1}+a\left(\bar{y}_{1}+W_{c}^{d}-k_{e} p_{i m}\right)+\frac{1}{\tau}\left(\bar{y}_{1}+W_{c}^{d}\right) \\
w_{2}-k_{2}\left(k_{e} p_{i m}+W_{f}\right)
\end{array}\right) .
\end{aligned}
$$

Introducing a new coordinate $z=p_{i m}^{\mu}-\left(p_{i m}^{e}\right)^{\mu}$ and rendering from new inputs $w_{1}, w_{2}$ to the outputs $\bar{y}_{1}, \bar{y}_{2}$, the system becomes

$$
\begin{aligned}
\dot{y}_{1} & =w_{1}, \\
\bar{y}_{2} & =w_{2}, \\
\dot{z} & =k_{z}\left(b-\frac{1}{\tau}\right) y_{1}+f_{z}-k_{z} w_{1}-\frac{k_{z} b}{k_{e}} w_{2},
\end{aligned}
$$

where

$$
k_{z}=\mu p_{i m}^{\mu-1} \frac{k_{1}}{b+a}
$$




$$
f_{z}=k_{z}\left(\left(b-\frac{1}{\tau}\right) W_{c}^{d}+b \frac{k_{2}}{k_{e}} W_{f}+\left(k_{2}-k_{e}\right) p_{i m} b\right) .
$$

\section{Construction of the control law}

To design a robust controller, we construct the control Lyapunov function of the form

$$
\begin{aligned}
& V\left(\overline{y_{1}}, \overline{y_{2}}, z\right) \\
& =c_{1} \bar{y}_{1}^{2}+c_{2} \bar{y}_{2}^{2}+c_{3} z^{2}+c_{4} \bar{y}_{1} z+c_{5} \bar{y}_{2} z+c_{6} \bar{y}_{1} \bar{y}_{2} .
\end{aligned}
$$

According to the definition of $V$ to be a CLF for the system, we have $V=L_{f} V+L_{g} V u \leq 0$. We use the equivalent condition such that $L_{g} V=0$ implies $L_{f} V \leq 0$ for all $\left(\overline{y_{1}}, \overline{y_{2}}, z\right) \neq 0$.

To design a control law, we obtain the sufficient condition for $V$ to be a CLF, and for an appropriately chosen positive scalar function $\gamma_{0}$ we get the control law

$$
u(x)=-\frac{1}{2} \gamma_{0}\left(L_{g} V\right)^{T}(x) .
$$

Theorem 1. For the system (11), the sufficient conditions for the function (14) to be a CLF are

$$
\left\{\begin{aligned}
d_{1} & >0 \\
d_{2} & >0 \\
d_{2} & >\frac{1}{2} d_{1} \max \{|z|\},
\end{aligned}\right.
$$

where

$$
\begin{gathered}
d_{1}^{2}=\left(2 c_{3}+c_{4} c_{21}+c_{5} c_{22}\right) k_{z}\left(\frac{1}{\tau}-b\right) c_{21}, \\
d_{2}=\frac{\left(2 c_{3}+c_{4} c_{21}+c_{5} c_{22}\right) f_{z}}{2 d_{1}}, \\
c_{11}=\frac{c_{6}-\frac{k_{z} b}{k_{e}} c_{4}}{2 c_{1}-k_{z} c_{4}}, \\
c_{22}=\frac{\frac{k_{z} b}{k_{e}} 2 c_{3}-c_{5}-c_{11}\left(k_{z} 2 c_{3}-c_{4}\right)}{2 c_{2}-\frac{k_{z} b}{k_{e}} c_{5}+c_{11}\left(k_{z} c_{5}-c_{6}\right)}, \\
c_{21}=\left(\frac{k_{z} 2 c_{3}-c_{4}}{2 c_{1}-k_{z} c_{4}}\right)+\left(\frac{k_{z} c_{5}-c_{6}}{2 c_{1}-k_{z} c_{4}}\right) c_{22} .
\end{gathered}
$$

The proof of this theorem in included in the Appendix.

Remark 1. Note that the condition (16) of Theorem 1 can be transformed to the form

$$
\max \{|z|\} c_{21}+W_{c}^{d}>0,
$$

(see Appendix for details).
Having constructed the CLF, we employ it to obtain an inverse optimal control law which guarantee robustness properties. Because $V$ is a CLF for the system (11), it is a CLF for the system (10) obtained by feedback transformations. Then the redesign control law takes the form

$$
\left(\begin{array}{l}
u_{1} \\
u_{2}
\end{array}\right)=-\frac{1}{2} \gamma_{0}\left(\begin{array}{c}
L_{g_{1} V} \\
L_{g_{2} V}
\end{array}\right) .
$$

For the system (11) having $\dot{z}=\mu p_{i m}^{\mu-1} \dot{p}_{i m}$, the general derivative of $V$ becomes

$$
\begin{aligned}
\dot{V} & \\
= & \left(2 c_{1} \bar{y}_{1}+c_{4} z+c_{6} \bar{y}_{2}\right) \\
& \times\left[-a\left(\bar{y}_{1}+W_{c}^{d}-k_{e} p_{i m}\right)\right. \\
& \left.-\frac{1}{\tau}\left(\bar{y}_{1}+W_{c}^{d}\right)-a u_{1}+b u_{2}\right] \\
& +\left(2 c_{2} \bar{y}_{2}+c_{5} z+c_{6} \bar{y}_{1}\right)\left[k_{2}\left(p_{i m} k_{e}+W_{f}\right)\right. \\
& \left.+k_{2} u_{1}-k_{2} u_{2}\right] \\
& +\mu p_{i m}^{\mu-1}\left(2 c_{3} z+c_{4} \bar{y}_{1}+c_{5} \bar{y}_{2}\right) \\
& \times\left(k_{1}\left(\bar{y}_{1}+W_{c}^{d}-k_{e} p_{i m}+u_{1}\right)\right) .
\end{aligned}
$$

We obtain

$$
\begin{aligned}
L_{g_{1} V}= & \bar{y}_{1}\left(-a 2 c_{1}+c_{6} k_{2}+c_{4} k \mu p_{1}^{\mu-1}\right) \\
& +\bar{y}_{2}\left(-a c_{6}+k_{2} 2 c_{2}+c_{5} k_{1} \mu p_{1}^{\mu-1}\right) \\
& +z\left(-a c_{4}+k_{2} c_{5}+2 c_{3} k_{1} \mu p_{1}^{\mu-1}\right) \\
L_{g_{2} V}= & \bar{y}_{1}\left(b 2 c_{1}-k_{2} c_{6}\right)+\bar{y}_{2}\left(b c_{6}-k_{2} 2 c_{2}\right) \\
& +z\left(b c_{4}-k_{2} c_{5}\right) .
\end{aligned}
$$

To apply the domination redesign control law (6), we center the controls at their setpoint values,

$$
u_{1}=v_{1}-W_{e g r}^{d}, \quad u_{2}=v_{2}-\left(W_{c}^{d}+W_{f}\right) .
$$

We choose a constant matrix

$$
\gamma_{0}=\left(\begin{array}{cc}
\gamma_{1} & 0 \\
0 & \gamma_{2}
\end{array}\right) .
$$

Finally, we center the controls for the system (1), $v_{1}$ and $v_{2}$, and we obtain the control law

$$
\begin{aligned}
u_{1} & \\
= & W_{e g r}^{d}+\gamma_{1}\left[\left(W_{c}-W_{c}^{d}\right)\left(-2 a c_{1}+c_{6} k_{2}+c_{4} k \mu p_{1}^{\mu-1}\right)\right. \\
& +\left(p_{e m}-p_{e m}^{e}\right)\left(-a c_{6}+2 k_{2} c_{2}+c_{5} k_{1} \mu p_{1}^{\mu-1}\right) \\
& \left.\left(p_{i m}^{\mu}-\left(p_{i m}^{e}\right)^{\mu}\right)\left(-a c_{4}+k_{2} c_{5}+2 c_{3} k_{1} \mu p_{1}^{\mu-1}\right)\right],
\end{aligned}
$$


$u_{2}$

$$
\begin{aligned}
= & \left(W_{c}^{d}+W_{f}\right)+\gamma_{2}\left[\left(W_{c}-W_{c}^{d}\right)\left(2 b c_{1}-k_{2} c_{6}\right)\right. \\
& +\left(p_{i m}^{\mu}-\left(p_{i m}^{e}\right)^{\mu}\right)\left(b c_{6}-2 k_{2} c_{2}\right) \\
& \left.++\left(p_{i m}^{\mu}-\left(p_{i m}^{e}\right)^{\mu}\right)\left(b c_{4}-k_{2} c_{5}\right)\right],
\end{aligned}
$$

where the controls for the system (1), $v_{1}$ and $v_{2}$, are expressed by (7).

\section{Experimental results in the AMESim virtual test-bench}

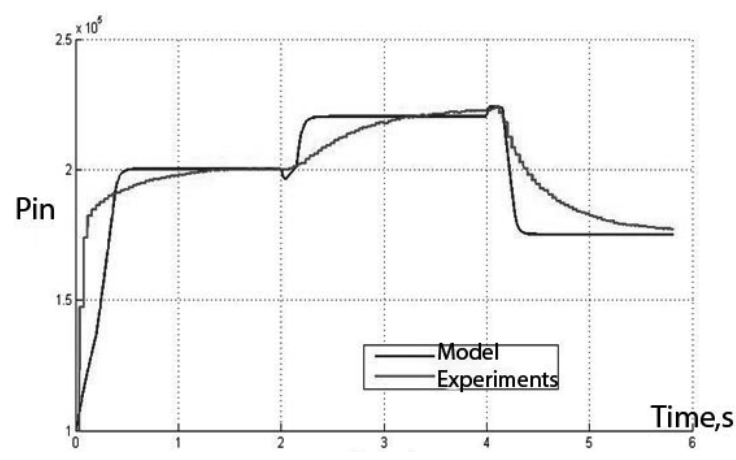

Fig. 3. Intake manifold pressure $P_{i m}$.

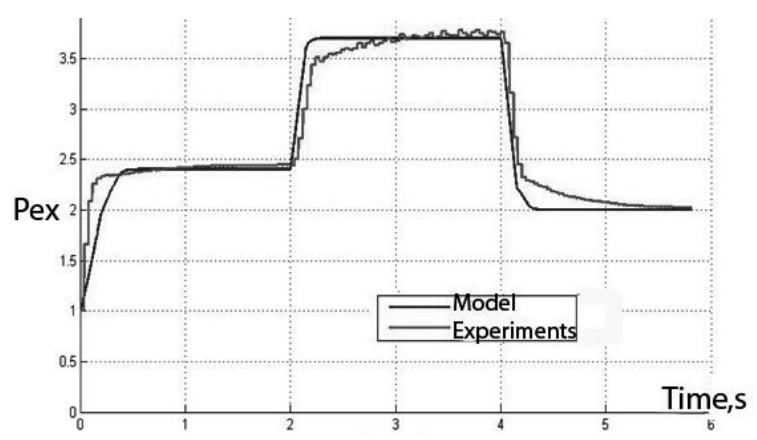

Fig. 4. Exhaust manifold pressure $P_{e m}$.

6.1. Model validation and generation of operating points. Optimal engine control is an important and challenging task and cannot be optimized separately from the calibration process and the operation strategy, and the control of diesel engines is mostly based on maps. A distinction between analytical and empirical models should be taken into account in order to derive good control performance. The presented analytical Jankovich model consists of a set of differential equations, and the empirical AMESim model depends on the availability of accurate measurements. Therefore, the accuracy of dynamical model validation is important since the control of diesel engines is mostly based on maps. The connection between the models is based on lookup-tables in which the measured data is stored.
Therefore, the calibration of the control unit is a time consuming process, requiring a large amount of measurement data and experienced engineers. In Figs. 3 and 4 , one can see model validation for the intake and the exhaust pressure, respectively. The inputs of these maps are the quantity of the fuel injected and the current engine speed. The maps are tuned according to low emissions and smoke. It is necessary to invert the flow model to

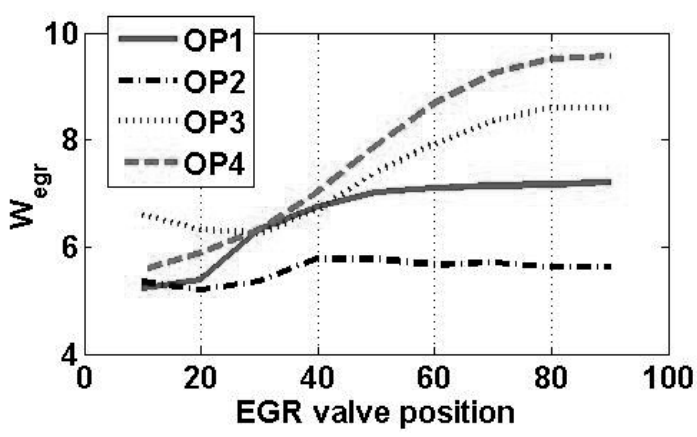

Fig. 5. EGR mass flow dependence.

obtain the EGR valve position and the VGT vane position commands, which are the control inputs to the model. The control performance was tested at three operating points: the engine speed varies from $n_{e}=2000(\mathrm{rpm})$ to 1800 (rpm), the mass of the fuel injected $u_{\delta}=34.9$ (mg/cycle), the valve positions $k_{\text {egr }}(\%)=20,40,60$ and $k_{v g t}(\%)=$ 40, 40,30, respectively. The turbine and compressor mass flow rates and their dependence on the valve positions were determined and collected into the look-up table in order to use them in the input transformation block. By inversion of the flow control inputs, the obtained EGR valve position and the VGT vane position commands are passed on to the engine. In Fig. 5 some simulation results are presented for the EGR mass flow dependence of the valve. These experiments were conducted on the AMESim platform and cover a large operating region. Furthermore, by inversion of the flow control inputs, the obtained EGR valve position and VGT vane position commands are passed on to the engine.

6.2. Control validation. All the model components of this virtual testbed are taken from libraries included in the software.

The general performance parameters were taken from the static engine data and the reference values for the operating points were obtained from simulation experiments in the AMESim software. The design parameters $\gamma_{1}, \gamma_{2}$ and $c_{1}, c_{2}, c_{3}, c_{4}, c_{5}, c_{6}$ provide degrees of freedom for the best control performance. Once calibrated, these parameters were held constant throughout the operating region. For satisfactory 


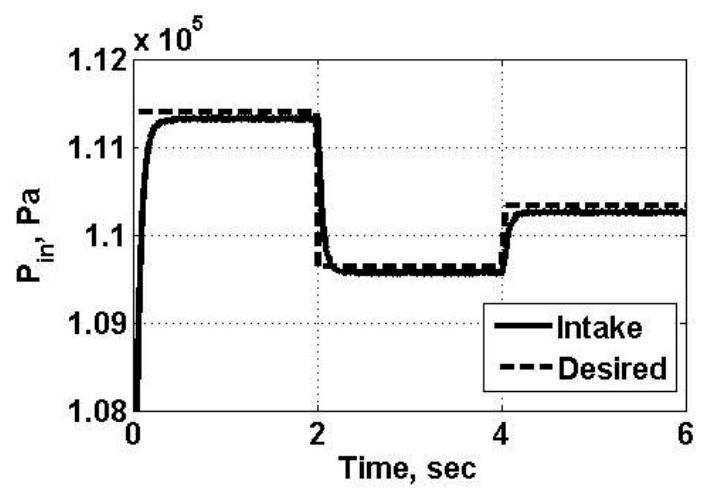

Fig. 6. Desired and actual value of intake manifold pressure.

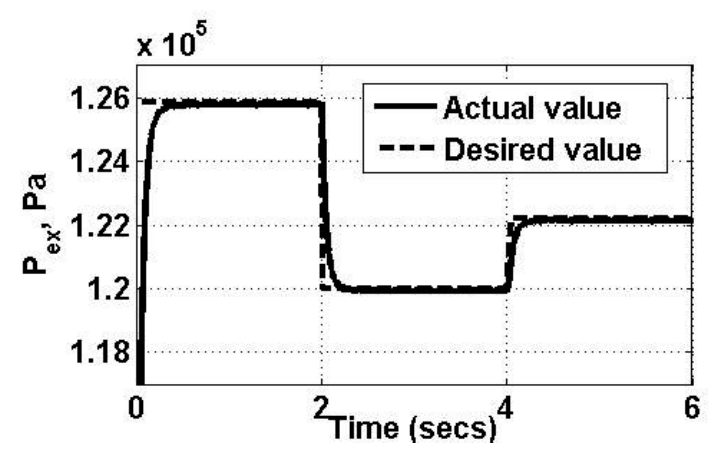

Fig. 7. Desired and actual value of exhaust manifold pressure.

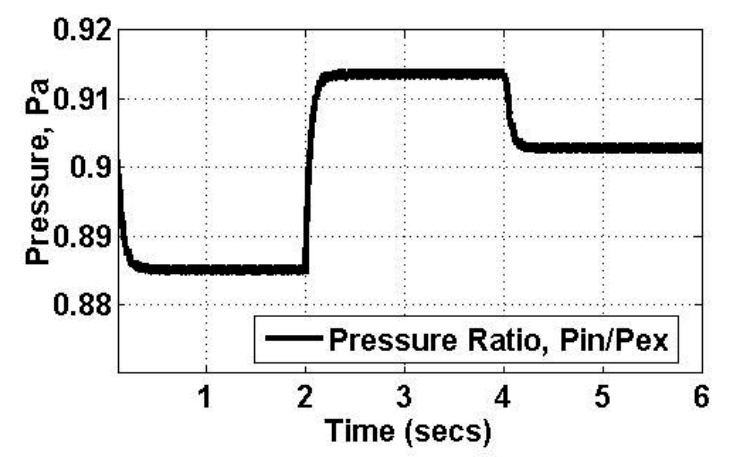

Fig. 8. Pressure ratio $P_{i m} / P_{e m}$.

regulation of the EGR flow rate, it is essential to monitor the behavior of the pressure ratio.

Figure 8 depicts the achieved pressure ratio trajectory, as well as the smooth profile. This is attributable to the model inversion approach that was used to estimate the EGR valve position and is sensitive to the manifold pressure ratio. Figures 6 and 7 show the intake and the exhaust manifold pressure profiles with desirable smooth trajectories. Figures 9 and 10 give the desired flow profiles for the compressed air flow rate and the turbine flow that were to be achieved via the EGR and the VGT

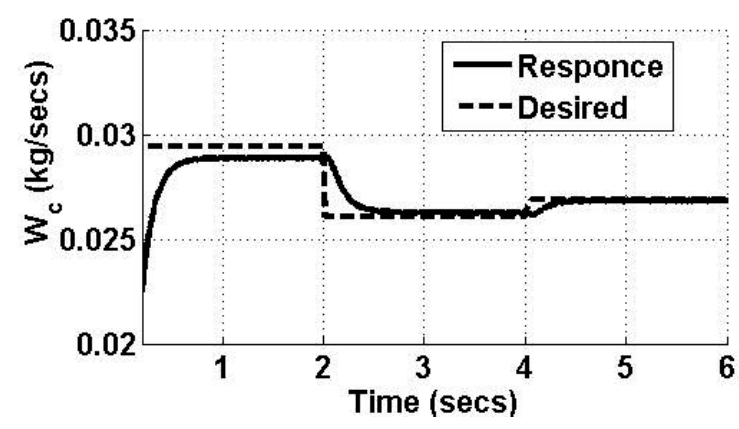

Fig. 9. Response of compressor mass flow rate $W_{c}$.

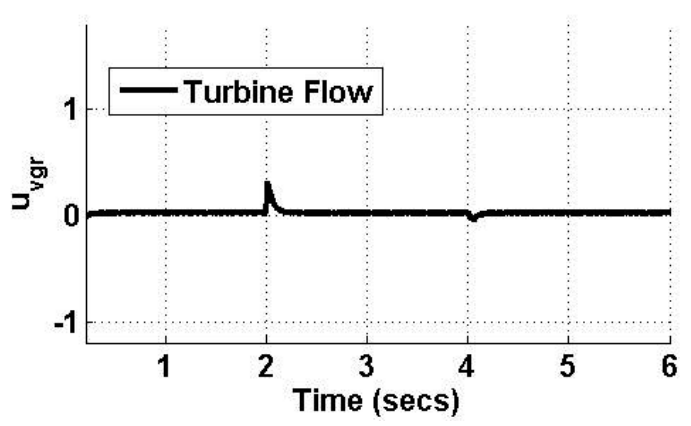

Fig. 10. Response of turbine mass flow rate $W_{t}$.

control input regulation. Therefore, only a limited number of parameters need to be tuned on the engine.

6.3. Simulation and comparison with PID. The CLF-based control performance as well as the PID controller were tested at the same four operating points $n_{e}=2000(\mathrm{rpm})$ and $2500(\mathrm{rpm})$, injection duration 1.2 (ms) and $1.8(\mathrm{~ms})$, valve positions $u_{\text {egr }}(\%)=20,70,10$ and $u_{v g t}(\%)=20,30,60$ (see Table 2).

Table 8. Operating points used in simulation.

\begin{tabular}{|l|c|c|c|c|}
\hline Parameter & OP 1 & OP 2 & OP 3 & OP 4 \\
\hline \hline$n_{e}(\mathrm{rpm})$ & 2000 & 2000 & 2000 & 2500 \\
\hline $\begin{array}{l}\text { Injection } \\
\text { duration } \\
(\mathrm{ms})\end{array}$ & 1.2 & 1.8 & 1.2 & 1.8 \\
\hline$u_{\text {egr }}(\%)$ & 20 & 70 & 70 & 10 \\
\hline$u_{v g t}(\%)$ & 20 & 30 & 20 & 60 \\
\hline
\end{tabular}

Figure 13 depicts the pressure ratio trajectory. Figures 11 and 12 show the intake and the exhaust manifold pressure profiles. Figure 14 gives the desired flow profile for the compressed air flow rate. Figures 17 and 18 show the intake and the exhaust manifold pressures of the PID controller. Figures 15 and 16 show satisfactory regulation without oscillations of the EGR flow rate and 


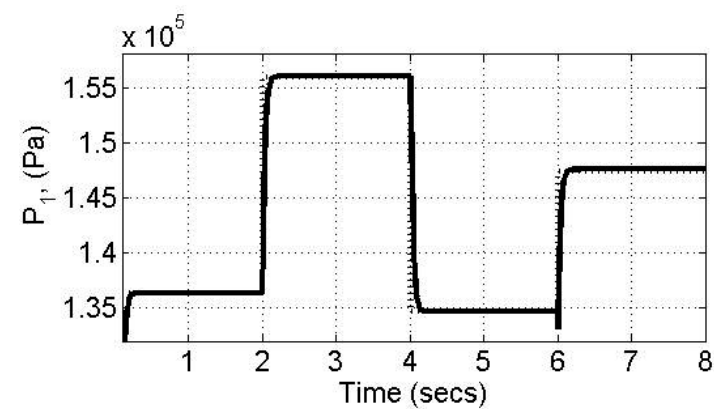

Fig. 11. CLF-based controller. Desired and actual value of intake manifold pressure $P_{i m}$.

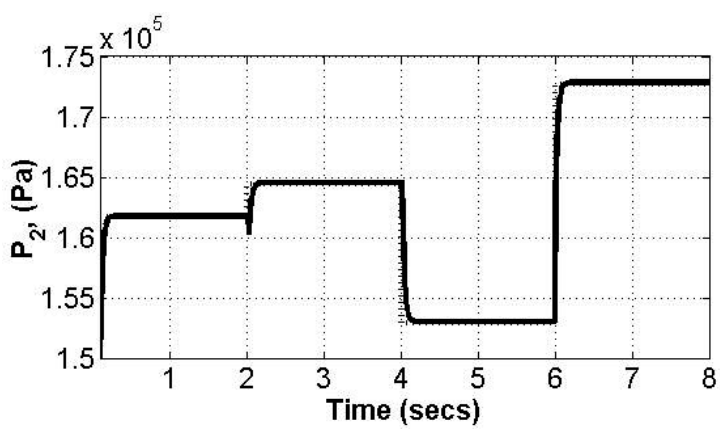

Fig. 12. CLF-based controller. Desired and actual value of exhaust manifold pressure $P_{e m}$.

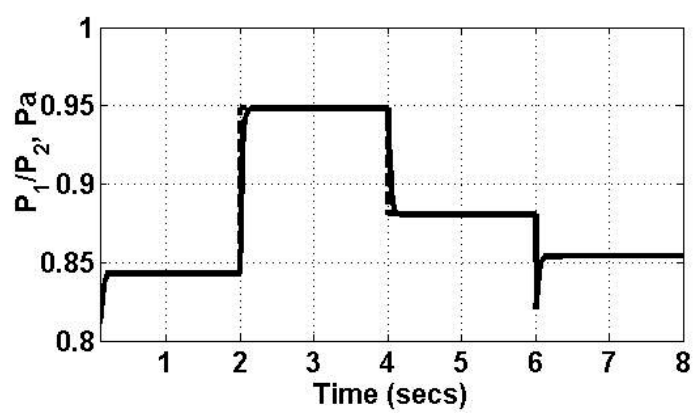

Fig. 13. CLF-based controller. Desired and actual value of exhaust manifold pressure $P_{e m}$.

the turbine mass flow rate of the CLF-based controller in comparison to the PID controller, shown in Figs. 19 and 20.

Feasibility, performances and robustness of CLF-based control schemes as well as PID control can be firstly evaluated on the model and secondly validated experimentally on the engine. The advantages and the effectiveness of CLF-based nonlinear control are concluded and results show that PID gives slower control and oscillation compared with CLF, and CLF gives no oscillations and provides a robust trajectory. The developed CLF-based nonlinear control approach gives a fast increase in the air intake, and slow degradation in

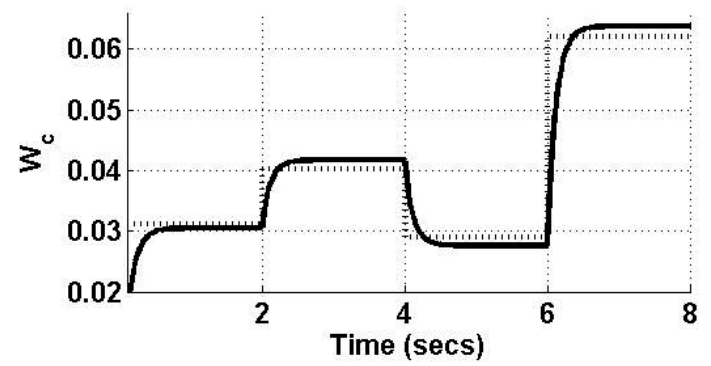

Fig. 14. CLF-based controller. Response of compressor mass flow rate $W_{c}$.

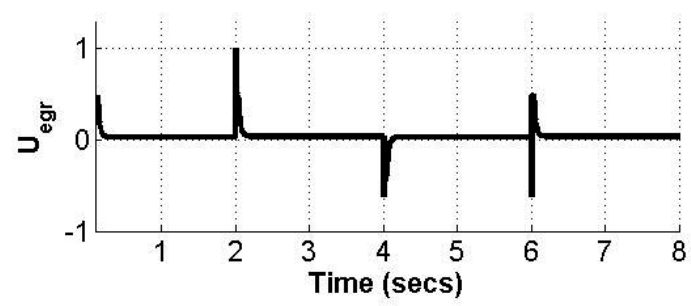

Fig. 15. CLF-based EGR control

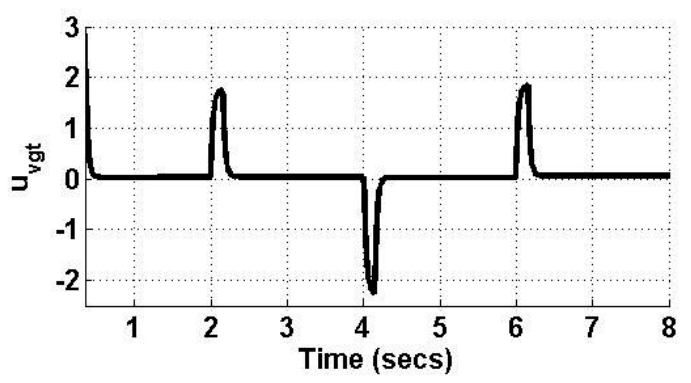

Fig. 16. CLF-based VGT control.

performances. Depending on the choice of the control design method, the controllers then have to be fine-tuned experimentally on the engine. However, without this fine-tuning, the controller may not perform adequately at some operating points.

\section{Experimental results from the caterpillar testbed}

7.1. Operating points. The operating points for the designed CLF-based control strategy were selected as shown in Table 9.

The reference values for the operation points were obtained from Caterpillar testbed experiments. These experiments cover a large operating region. In order to validate the CLF controller, we consider two subregions presented in Fig. 21. The first one is [400 s, $620 \mathrm{~s}]$ at an engine speed of $1600 \mathrm{rpm}$ and a load of 42, and the second 


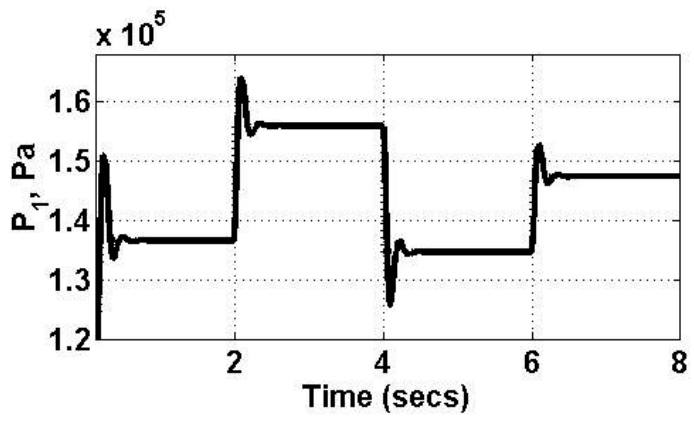

Fig. 17. PID controller. Intake manifold pressure.

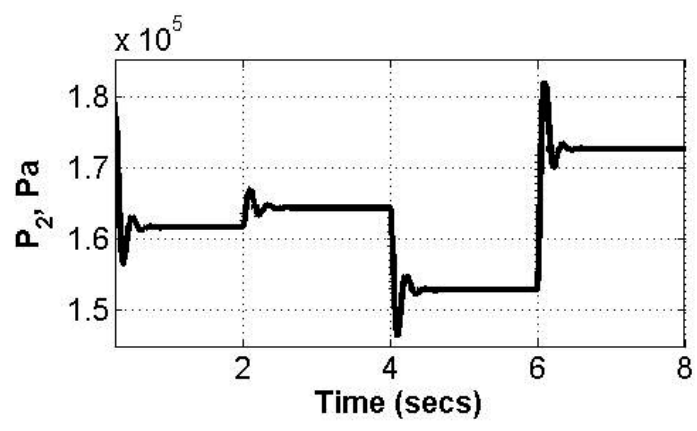

Fig. 18. PID controller. Exhaust manifold pressure.

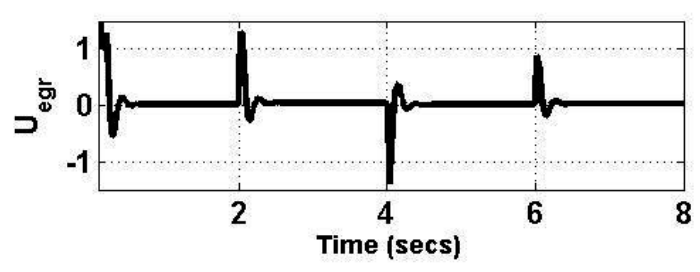

Fig. 19. EGR input of a PID controller.

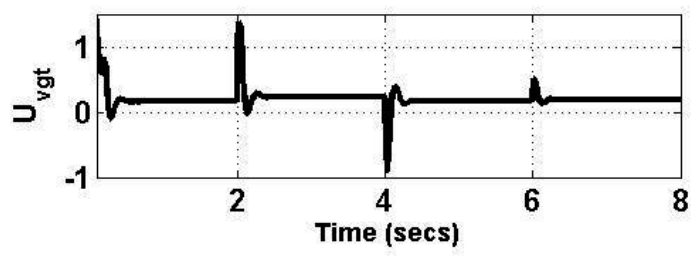

Fig. 20. VGT input of a PID controller.

Table 9. Operation points used in simulation.

\begin{tabular}{|l|c|c|}
\hline Parameter & Operating point 1 & Operating point 2 \\
\hline \hline$n_{e}(\mathrm{rpm})$ & 1600 & 1800 \\
\hline load & 42 & 50 \\
\hline$u_{\text {egr }}(\%)$ & 20 & 40 \\
\hline$u_{\text {vgt }}(\%)$ & 42 & 50 \\
\hline
\end{tabular}

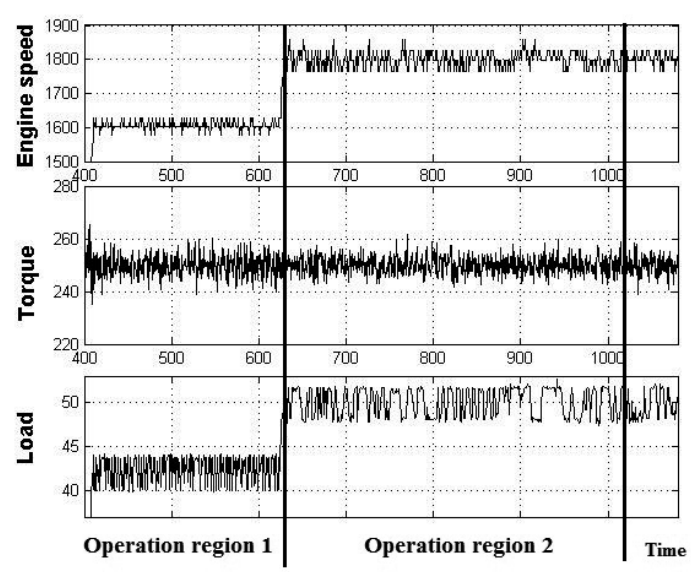

Fig. 21. Operating region of the test experiment.

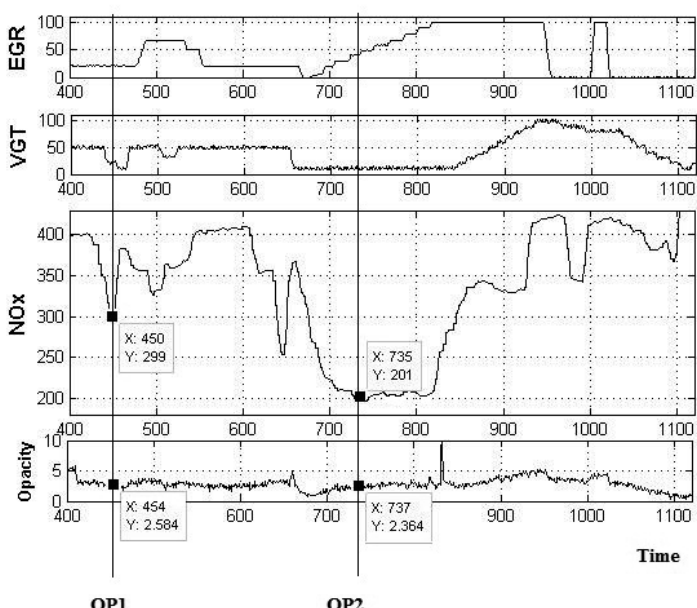

Fig. 22. Selection of operating points

one is $[620 \mathrm{~s}, 1100 \mathrm{~s}]$ at an engine speed of $1800 \mathrm{rpm}$ and a load of 50 .

The EGR and VGT control inputs and their corresponding amounts of $N O_{x}$ and the opacity are presented in Fig. 22. Hence, two operating points were selected based on a tradeoff between the minimum of $N O_{x}$ and the opacity (see Table 9). For the inversion we use the expressions of the EGR mass flow and the turbine mass flow (Section 3.3).

7.2. Experimental results. The control strategy was tested on a six-cylinder diesel engine model which was built using MatLab. Therefore, only a limited number of parameters need to be tuned on the engine. Figure 25 depicts the pressure ratio trajectory, which has a smooth 
profile. Figures 23 and 24 show the intake and exhaust manifold pressure with smooth profiles. Figures 26 and 27 demonstrate the EGR and VGT control inputs.

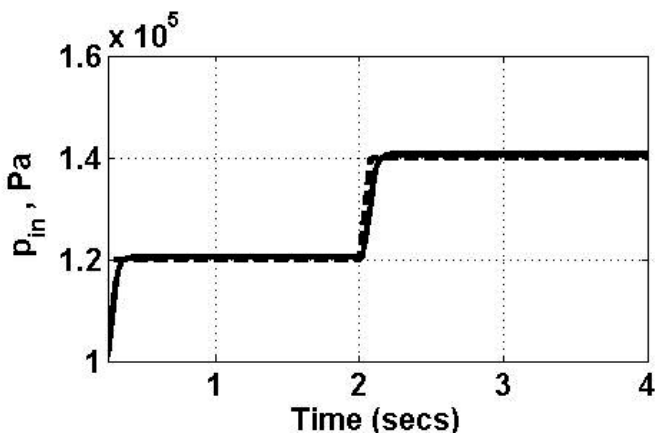

Fig. 23. Intake pressure and its reference.

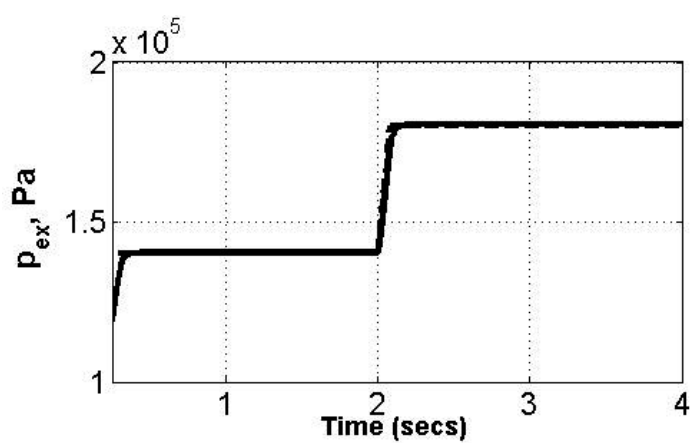

Fig. 24. Exhaust pressure and its reference.

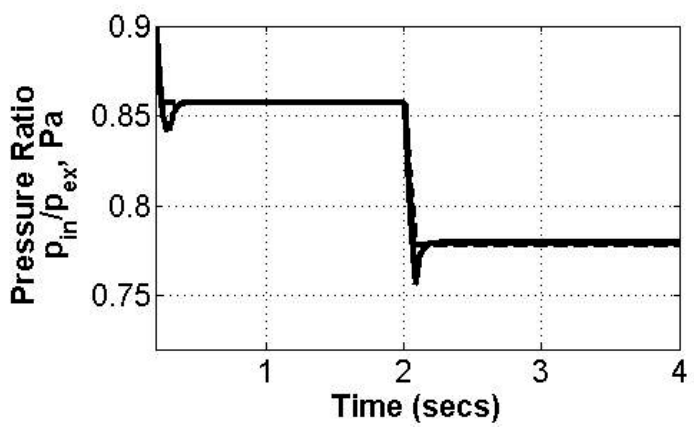

Fig. 25. Pressure ratio.

Depending on the choice of the control design method, the controllers have to be fine-tuned experimentally on the engine. Therefore, a model-based robust control design is beginning to find applications in the engine and automotive industry.

Remark 2. (Discussion and comparison with the LPV approach) The proposed approach will extend from the

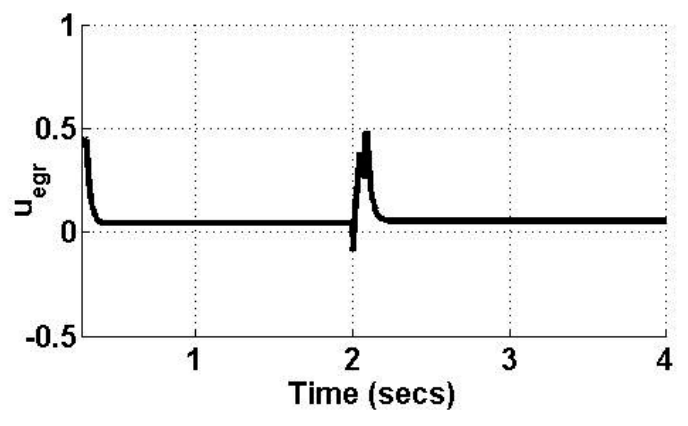

Fig. 26. EGR control input

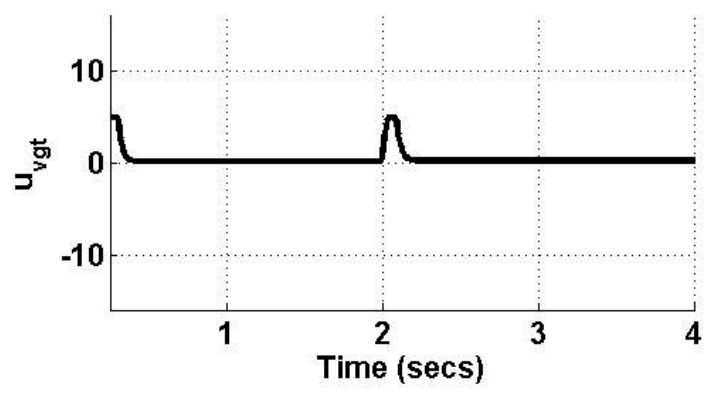

Fig. 27. VGT control input

trivial quadratic Lyapunov function case considered in various LPV approaches to a more general Lyapunov function with additional degrees of freedom. Compared with quadratic Lyapunov functions, this generalized Lyapunov function will help us to construct the resulting nonlinear control law so that the design objective can be optimized with respect to a given cost functional for good performance. Having the condition $L g_{1} V=0$, $L g_{2} V=0$ and $L_{f} V<0$ for the function $V$ to be a CLF, by manipulation of the parameters, it is possible to verify the condition $J \rightarrow$ min in order to evaluate the optimal cost criteria $J$. This parameter manipulation under the stability conditions improves control performance and can expand the stability region of nonlinear systems. By adopting a Lyapunov function by a computationally effective optimization approach to redesign the control law, it provides more freedom to achieve a higher performance level for the resulting generalized control gain.

Theoretically, compared with quadratic Lyapunov functions, this generalized Lyapunov function helps, to search for a best-fitted Lyapunov function and construct the resulting nonlinear control law so that the design objective can be optimized.

\section{Conclusions}

We developed a CLF-based nonlinear controller for the flows of VGT-EGR systems in order to regulate 
the oxygen-fuel ratio and the intake manifold EGR fraction, and to minimize the $N O_{x}$ emission and the smoke. The more general control Lyapunov function considered provides additional degrees of freedom, which gives better control performances, satisfies the stability condition and guarantees the global convergence of the error system. This nonlinear control approach offers a fast increase in variable performance and graceful degradation. Experiments in the biodiesel engine Caterpillar testbed and a virtual test-bench for a four-cylinder diesel engine show the effectiveness of this approach.

In the future work, a performance comparison with multiple model approaches, LPV and Takagi-Sugeno approaches as well as other types of nonlinear controller will be considered. Robustness regarding the disturbances and parametric uncertainties, measurement noise and reliability features will be investigated.

\section{Acknowledgment}

This work was produced in the framework of SCODECE (Smart COntrol and Diagnosis for Economic and Clean Engine), a European territorial cooperation project part-funded by the European Regional Development Fund (ERDF) through the INTERREG IV A 2 Seas Programme, Lille, France.

\section{References}

Abidi, I., Bosche, J., Hajjaji, A.E. and Aguilera-Gonzales, A. (2013). Fuzzy robust tracking control with pole placement for a turbocharged diesel engine, Proceedings of the 21st Mediterranean Conference on Control and Automation (MED'13), Crete, Greece.

Adi, G., Hall, C., Snyder, D., Bunce, M., Satkoski, C., Kumar, S., Garimella, P., Stanton, D. and Shaver, G. (2009). Soy-biodiesel impact on nox emissions and fuel economy for diffusion-dominated combustion in a turbo-diesel engine incorporating exhaust gas recirculation and common rail fuel injection, Energy \& Fuels 23(12): 5821-5829.

Boulkroune, B., Djemili, I., Aitouche, A. and Cocquempot, V. (2013). Robust nonlinear observer design for actuator fault detection in diesel engines, International Journal of Applied Mathematics and Computer Science 23(3): 557-569, DOI: 10.2478/amcs-2013-0042.

Cook, J., Sun, J., Buckland, J., Kolmanovsky, I.V., Peng, H. and Grizzle, W. (2006). Automotive powertrain control-a survey, Asian Journal of Control 8(3): 237-260.

Delaleau, E., Louis, J.-P. and Ortega, R. (2001). Modeling and control of induction motors, International Journal of Applied Mathematics and Computer Science 11(1): 105-129.

Djemili, I., Aitouche, A. and Cocquempot, V. (2012). Fault tolerant control of internal combustion engine subject to intake manifold leakage, Preprints of the 8th IFAC Symposium on Fault Detection, Supervision and Safety of Technical Processes (SAFEPROCESS), Mexico City, Mexico.

Isidori, A. (1989). Nonlinear Control Systems, 2nd Edn., Springer Verlag, Berlin.

Jankovic, M., Jankovic, M. and Kolmanovsky, I. (1998). Robust nonlinear controller for turbocharged diesel engines, Proceedings of the American Control Conference, Philadelphia, PA, USA, pp. 1389-1395.

Jankovic, M., Jankovic, M. and Kolmanovsky, I. (2000). Constructive Lyapunov control design for turbocharged diesel engines, IEEE Transactions on Control Systems Technology 8(2): 288-299.

Kao, M. and Moskwa, J. (1995). Turbocharged diesel engine modeling for nonlinear engine control and state estimation, ASME Journal of Dynamic Systems, Measurement and Control 117(1): 20-30.

Kuzmych, O., Aitouche, A., Bosche, J. and El-Hajjaji, A. (2012). Robust nonlinear observer with $\mathrm{H}^{\infty}$ performance analysis of a turbocharged diesel engine, International Symposium on Security and Safety of Complex Systems, 2SCS12, Agadir, Morocco.

Lansky, L. (2008). Diesel Engine Modelling and Control, Master's thesis, Czech Technical University in Prague, Prague.

Sepulchre, R., Jankovic, M. and Kokotovic, P. (1997). Constructive Nonlinear Control, Springer Verlag, Berlin.

Simani, S. (2013). Residual generator fuzzy identification for automotive diesel engine fault diagnosis, International Journal of Applied Mathematics and Computer Science 23(2): 419-438, DOI: 10.2478/amcs-2013-0032.

Stefanopoulou, A.G., Kolmonovsky, I. and Freudenberg, J.S. (2000). Control of variable geometry turbocharged diesel engines for reduced emissions, Transactions on Control System Technology 8(4): 733-745.

Takagi, T. and Sugeno, M. (1985). Fuzzy identification of systems and its applications to modeling and control, IEEE Transactions on Systems, Man and Cybernetics 15(1): 116-132.

Tanaka, K. and Wang, H.O. (2001). Fuzzy Control Systems Design and Analysis: A Linear Matrix Inequality Approach, Wiley, New York, NY.

Tomera, M. (2010). Nonlinear controller design of a ship autopilot, International Journal of Applied Mathematics and Computer Science 20(2): 271-280, 10.2478/v10006-010-0020-8.

Upadhyay, D., Utkin, V. and Rizzoni, G. (2002). Multivariable control design for intake flow regulation of a diesel engine using sliding mode, 15th Triennial World Congress, Barcelona, Spain, Vol. 15, Part 1.

Utkin, V. (1992). Sliding Modes in Control Optimization, Springer Verlag, Berlin/New York, NY.

Wahlstrom, J. and Eriksson, L. (2011a). Modeling diesel engines with a variable-geometry turbocharger and exhaust gas recirculation by optimization of model parameters for 
capturing non-linear system dynamics, Proceedings of the Institution of Mechanical Engineers, Part D: Journal of Automobile Engineering 225(7): 959-986.

Wahlstrom, J. and Eriksson, L. (2011b). Nonlinear EGR and VGT control with integral action for diesel engines, Oil and Gas Science and Technology 66(4): 573-586.

Wahlstrom, J., Eriksson, L., Nielsen, L. and Pettersson, M. (2005). PID controllers and their tuning for EGR and VGT control in diesel engines, 16th IFAC World Congress, Prague, Czech Republic

Witkowska, A. and Śmierzchalski, R. (2012). Designing a ship course controller by applying the adaptive backstepping method, International Journal of Applied Mathematics and Computer Science 22(4): 985-997, DOI: 10.2478/v10006-012-0073-y.

Yarza, A., Santibanez, V. and Moreno-Valenzuela, J. (2013). An adaptive output feedback motion tracking controller for robot manipulators: Uniform global asymptotic stability and experimentation, International Journal of Applied Mathematics and Computer Science 23(3): 599-611, DOI: 10.2478/amcs-2013-0045.

Zemouche, Z., Boutayeb, M. and Bara, G. (2004). Observer design for nonlinear systems: An approach based on the differential mean value theorem, Proceedings of the 44th IEEE Conference on Decision and Control/European Control Conference, Seville, Spain, 2005.

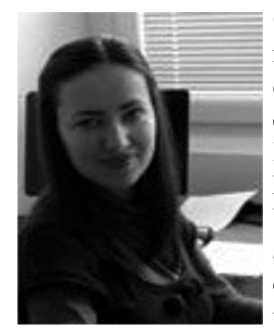

Olena Kuzmych received the Ph.D. degree in mathematical modeling and computational methods at the Department of Complex System Modeling, Taras Shevchenko National University of Kyiv, Ukraine (2008). Now she is a postdoc with Hautes Études d'Ingénieurs and LAGIS CNRS UMR 8219, Lille, France. Within her research activity she works on stability, state estimations, control, observation problems of nonlinear systems, and their applications in science and engineering. The research area also includes diesel engine model analysis, dynamical hybrid systems, time-switched systems, and Lurie regulation systems.

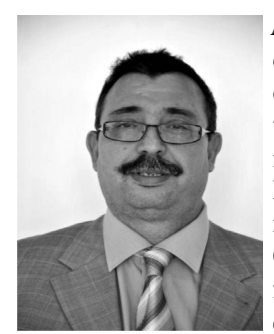

Abdel Aitouche is a professor in Hautes Études d'Ingénieurs de Lille, France (Graduate School of Engineering). $\mathrm{He}$ is a researcher at Laboratoire d'Automatique, Génie Informatique et Signal de Lille (associated with the CNRS, French National Center for Scientific Research). He is member of the IEEE and MCA (Mediterranean Control Society). His research interests concern fault tolerant systems, nonlinear control, fault tolerant control and model based fault detection and diagnosis. Their application domains are mainly intelligent, embedded systems, process engineering, combustion engine, fuel cells and renewable energy (wind, PV).

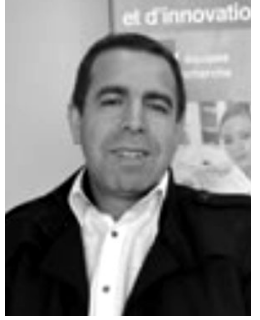

Ahmed El Hajjaji received the Ph.D. degree in automatic control and the HDR degree from the University of Picardie Jules Verne, France, in 1993 and 2000, respectively. From 1994 to 2003, he was an associate professor with the University of Picardie Jules Verne, where he is currently a full professor and the director of the Professional Institute of Electrical Engineering and Industrial Computing, and has been the head of the research team for control and vehicles with the Modeling, Information, and Systems Laboratory since 2001. His research interests include fuzzy control, vehicle dynamics, fault-tolerant control, neura networks, maglev systems, and renewable energy.

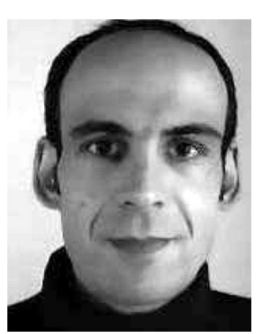

Jerome Bosche was born in Tulle, France, in 1975. From 1999 to 2004, he was with LAI (Laboratoire d'Automatique et d'Informatique Industrielle) of Poitiers. He received the M.Sc degree with specialization in analysis and control from the University of Poitiers in 2000, and the $\mathrm{Ph} . \mathrm{D}$. degree from the same university in 2003 . He kept on working for two years at LAII. Since 2005, he has been with the Laboratory of MIS (Modelling Information and Systems) in Amiens, France, as a researcher. He is also an assistant professor of the Department of Sciences of the University of Picardie Jules Verne in Amiens. His current research interests include robust analysis and output feedback stabilization applied to vehicles and renewable energy systems.

\section{Appendix}

\section{Proof of Theorem 1}

By calculating the derivative of the Lyapunov function (14), we obtain

$$
\begin{aligned}
\dot{V}= & 2 c_{1} \bar{y}_{1} \dot{\bar{y}}_{1}+2 c_{2} \bar{y}_{2} \dot{\bar{y}}_{2}+2 c_{3} z \dot{z}+c_{4} \bar{y}_{1} \dot{z} \\
& +c_{4} z \dot{\bar{y}}_{1}+c_{5} \bar{y}_{2} \dot{z}+c_{5} z \dot{\bar{y}}_{2}+c_{6} \bar{y}_{1} \dot{\bar{y}}_{2}+c_{6} \bar{y}_{2} \dot{\bar{y}}_{1}
\end{aligned}
$$

and transform this expression into

$$
\begin{aligned}
\dot{V}= & \dot{\bar{y}}_{1}\left(2 c_{1} \bar{y}_{1}+c_{4} z+c_{6} y_{2}\right)+\dot{\bar{y}}_{2}\left(2 c_{2} \bar{y}_{2}+c_{5} z+c_{6} \bar{y}_{1}\right) \\
& +\dot{z}\left(2 c_{3} z+c_{4} y_{1}+c_{5} y_{2}\right) .
\end{aligned}
$$

Substituting the state derivatives, we collect the control inputs,

$$
\begin{aligned}
\dot{V}= & w_{1}\left(2 c_{1} \bar{y}_{1}+c_{4} z+c_{6} \bar{y}_{2}-k_{z}\left(2 c_{3} z+c_{4} \bar{y}_{1}+c_{5} \bar{y}_{2}\right)\right) \\
= & w_{2}\left(2 c_{2} \bar{y}_{2}+c_{5} z+c_{6} \bar{y}_{1}\right. \\
& \left.-\frac{k_{z} b}{k_{e}}\left(2 c_{3} z+c_{4} \bar{y}_{1}+c_{5} \bar{y}_{2}\right)\right) \\
& +\left(2 c_{3} z+c_{4} \bar{y}_{1}+c_{5} \bar{y}_{2}\right)\left(k_{z}\left(b-\frac{1}{\tau}\right) y_{1}+f_{z}\right) .
\end{aligned}
$$

Assume that $L_{g_{1}} V=0, L_{g_{2}} V=0$. Then the 
obtained system is

$$
\begin{aligned}
& 2 c_{1} \bar{y}_{1}+c_{4} z+c_{6} \bar{y}_{2}-k_{z} 2 c_{3} z-k_{z} c_{4} \bar{y}_{1} \\
& -k_{z} c_{5} \bar{y}_{2}=0, \\
& 2 c_{2} \bar{y}_{2}+c_{5} z+c_{6} \bar{y}_{1}-\frac{k_{z} b}{k_{e}} 2 c_{3} z \\
& -\frac{k_{z} b}{k_{e}} c_{4} \bar{y}_{1}-\frac{k_{z} b}{k_{e}} c_{5} \bar{y}_{2}=0,
\end{aligned}
$$

giving

$$
\bar{y}_{1}=\frac{k_{z} c_{5} \bar{y}_{2}+k_{z} 2 c_{3} z-c_{4} z-c_{6} \bar{y}_{2}}{\left(2 c_{1}-k_{z} c_{4}\right)} .
$$

Substituting this in the second equation of (A4), we obtain

$$
\begin{array}{r}
2 c_{2} \bar{y}_{2}+c_{5} z+\frac{c_{6}-\frac{k_{z} b}{k_{e}} c_{4}}{2 c_{1}-k_{z} c_{4}}\left(k_{z} c_{5} \bar{y}_{2}+k_{z} 2 c_{3} z-c_{4} z\right. \\
\left.-c_{6} \bar{y}_{2}\right)-\frac{k_{z} b}{k_{e}} 2 c_{3} z-\frac{k_{z} b}{k_{e}} c_{5} \bar{y}_{2}=0 .
\end{array}
$$

Then, using [19], we obtain

$$
\bar{y}_{2}=\frac{\frac{k_{z} b}{k_{e}} 2 c_{3}-c_{5}-c_{11}\left(k_{z} 2 c_{3}-c_{4}\right)}{2 c_{2}-\frac{k_{z} b}{k_{e}} c_{5}+c_{11}\left(k_{z} c_{5}-c_{6}\right)} z
$$

and

$$
\begin{aligned}
\bar{y}_{1}= & \left(\frac{k_{z} 2 c_{3}-c_{4}}{2 c_{1}-k_{z} c_{4}}\right) z \\
& +\left(\frac{k_{z} c_{5}-c_{6}}{2 c_{1}-k_{z} c_{4}}\right) \\
& \times\left(\frac{\frac{k_{z} b}{k_{e}} 2 c_{3}-c_{5}-c_{11}\left(k_{z} 2 c_{3}-c_{4}\right)}{2 c_{2}-\frac{k_{z} b}{k_{e}} c_{5}-c_{11}\left(k_{z} c_{5}-c_{6}\right)}\right) z .
\end{aligned}
$$

Using (20) and 21, we obtain

$$
\bar{y}_{1}=c_{21} z, \bar{y}_{2}=c_{22} z \text {. }
$$

Consider the $L_{f} V$ component of the Lyapunov function derivative,

$$
L_{f} V=\left(2 c_{3} z+c_{4} \bar{y}_{1}+c_{5} \bar{y}_{2}\right)\left(k_{z}\left(b-\frac{1}{\tau}\right) \bar{y}_{1}+f_{z}\right),
$$

and prove that $L_{f} V<0$. We substitute A5 into the last expression in order to obtain

$$
\begin{aligned}
L_{f} V= & \left(2 c_{3} z+c_{4} c_{21} z+c_{5} c_{22} z\right) \\
& \left(k_{z}\left(b-\frac{1}{\tau}\right) c_{21} z+f_{z}\right) .
\end{aligned}
$$

Transform the last formula into

$$
\begin{aligned}
L_{f} V= & z^{2}\left(2 c_{3}+c_{4} c_{21}+c_{5} c_{22}\right) k_{z}\left(b-\frac{1}{\tau}\right) c_{21} \\
& +z\left(2 c_{3}+c_{4} c_{21}+c_{5} c_{22}\right) f_{z} .
\end{aligned}
$$

For the values of $d_{1}$ and $d_{2}$, we apply the formula $\left(d_{1} z+d_{2}\right)^{2}=d_{1}^{2} z^{2}+2 d_{1} d_{2} z+d_{2}^{2}$ and obtain

$$
-\left(\left(d_{1} z+d_{2}\right)^{2}-d_{2}^{2}\right)<0 \text {. }
$$

We consider the following two cases.

Case 1: $z>0$. Note that it is possible to choose the parameters $c_{1}, c_{2}, c_{3}, c_{4}, c_{5}, c_{6}$ such that $d_{2}>0$. Taking into account that $(1 / \tau-b)>0$, we conclude that

$$
d_{1}=\sqrt{\left(2 c_{3}+c_{4} c_{21}+c_{5} c_{22}\right) k_{z}\left(\frac{1}{\tau}-b\right) c_{21}}>0
$$

Case 2: $z<0$. From we obtain

$$
\left(d_{1} z+d_{2}\right)^{2}-d_{2}^{2}>0
$$

and

$$
d_{1}^{2}|z|^{2}-2 d_{1} d_{2}|z|>0 \Rightarrow d_{1}|z|>2 d_{2} .
$$

Then the condition $2 d_{2}<d_{1}|z|<d_{1} \max \{|z|\}$ holds. From the last formula and after collecting the results for both the cases $z>0$ and $z<0$, we obtain the condition (16) of the theorem. Hence, $V$ is a CLF for the system (11).

By substituting $d_{1}$ and $d_{2}$ into (A6), we get

$$
\begin{gathered}
\frac{d_{1}^{2}|z|-\left(2 c_{3}+c_{4} c_{21}+c_{5} c_{22}\right) f_{z}}{d_{1}}>0 \\
\frac{|z| k_{z}\left(\frac{1}{\tau}-b\right) c_{21}-f_{z}}{d_{1}}>0
\end{gathered}
$$

Having $d_{1}>0$, we get $|z| k_{z}(1 / \tau-b) c_{21}>f_{z}$. After substituting $f_{z}$ into this expression and taking into account $z<0$ and $(b-1 / \tau)<0$,

$$
|z|\left(\frac{1}{\tau}-b\right) c_{21}>-\left(\frac{1}{\tau}-b\right) W_{c}^{d} .
$$

From this we get $\max \{|z|\} c_{21}+W_{c}^{d}>|z| c_{21}+$ $W_{c}^{d}>0$. Finally, we obtain the following condition: $\max \{|z|\} c_{21}+W_{c}^{d}>0$, which has been pointed out in Remark 1.

Received: 12 August 2013 Revised: 15 January 2014 